\title{
Invasion of alien plant species and their impact on different ecosystems of Panchase Area, Nepal
}

\author{
S. Baral ${ }^{1 *}$, A. Adhikari', R. Khanal' ${ }^{2}$,Y. Malla' ${ }^{2}$, R. Kunwar ${ }^{3}$, B. Basnyat ${ }^{4}$, K. Gauli ${ }^{5}$ \\ and R. P. Acharya ${ }^{6}$
}

The aggressiveness of invasive alien plant species has been amidst the changing climate, which has necessitated further research in this area. The impact of invasive alien plant species in the Panchase area of Nepal was assessed through the forest resource assessment and other methodologies such as, household survey, group discussion, direct field observation, participatory cluster mapping, quadrat sampling, laboratory analysis, and GIS mapping. A total of nine major invasive species, in which Ageratum houstonianum and Ageratina adenophora were found spread throughout the ecosystem. The invasion was fueled by anthropogenic disturbances such as leaving the agricultural lands, fallow and degradation of habitat. As a consequence, native species such as Artemisia indica and Urtica dioica were outcompeted mostly in the fringes of fallow lands, agricultural lands and in the disturbed sites. The intrusion was, however, less in the forest area, implying that community-managed dense canopy forests are less susceptible to invasion and routine management can offset the negative effects of invasion. Even though many negative consequences of the invasion were observed in the study sites, the possibility of the economically exploiting the biomass of invasive alien plant species for generating income locally was noticed.

Key words: Climate change, disturbances, ecosystem, Invasive plants, Nepal, Panchase

$\mathrm{I}$ nvasive plants are exotic species that threaten native ecosystems, habitats or species (CBD, 2008). Introduced plant species and livestock spread like invasive or associated species, by displacing native species (Matthews and Brand, 2004; Mooney et al., 2005). The emergence of invasive alien plant species (IAPS), which are commonly referred to as weeds, is a major threat to the biodiversity and ecosystem services (Burgiel and Muir, 2010). The IUCN (2000) defines IAPS as exotic plants that have established themselves in natural or semi-natural ecosystems or habitats, and are agents of change, and threaten native biological diversity. On the other hand, the IPCC (2007) identifies climate change as one of the factors for the emergence of invasive plant species. Increase in atmospheric temperature and carbon dioxide concentrations are likely to increase invasion of plant species because of their adaptability and ability to disturb a broad range of biogeographic conditions and environments (Mooney and Hobbs, 2000). Lodge et al. (2006) concluded that IAPS endanger the environment, economy and human welfare. They also reduce the population of native or replace them all together, necessitate increased investment in agricultural activities and silviculture operations (Ricchardi et al., 2000), and disrupt prevailing vegetation dynamics and nutrient cycling (Richardson \& Higgins, 1998). The estimated worldwide damage from IAPS is estimated to be about US \$1.4 trillion a year, which is nearly 5 percent of the global economy (Stern, 2006). The IAPS impacts on the wide range of sectors including agriculture, forestry, aquaculture, trade and recreation. Since from the $17^{\text {th }}$ century, IAPS are the agents for nearly 40 percent of different animal extinctions for which cause is known (CBD, 2002).

\footnotetext{
${ }^{1}$ University of Natural Resources and Life Sciences, Vienna, Austria.*E-mail: sonybaral@gmail.com

${ }^{2}$ International Union for Conservation of Nature, Nepal

3 Department of Geosciences, Florida Atlantic University, US

${ }^{4}$ Institute of Forestry and University of Copenhagen, Denmark

5 Resource Identification and Management Society (RIMS) Nepal

${ }^{6}$ Practical Solutions, Kathmandu, Nepal
} 
The CBD (1992) has set global priorities, and guidelines on collecting information and on coordinating international actions on invasive alien species. The fifth IUCN World Park Congress, 2003 underlined the need for managing IAPS as an "emerging issue", which was further emphasized at the sixth World Park Congress, 2014. Nepal, being a signatory of the Convention on Biological Diversity (CBD), is required to prevent the introduction of IAPS and to control or eradicate those IAPS that threaten ecosystems, habitats and species (CBD, 1992). The approaches taken to combat invasive species, as well as the data on which they should be based, are, however, clearly inadequate to deal with the onslaught of invasive species in the country. Similarly, from a conservation perspective, there is little point to addressing the climate change if the biodiversity we are trying to protect has already been lost to invasive species.

The introduction and aggressiveness of IAPS are increasing especially on different land uses, in the changing climate. The problem of invasion is quite high in farmland and forests compared to other ecosystems (IUCN, 2014; Suwal et al., 2016). A total of 166 IAPS of Nepal are reported (Tiwari et al., 2005); however, effects of invasion and initiatives to manage IAPS and studies to research their dynamics have been very limited (Bhattarai et al., 2014). Although the first study of the IAPS of Nepal was carried out nearly five decades ago (Banerji, 1958), studies focusing on impacts and management of IAPS at species-, ecosystem- and socio-economic levels through eco-friendly approaches are few. Poudel and Thapa (2012) admit further research on the impacts of IAPS by focusing on the ecosystem and land use types from the reviewed of 43 similar studies related to IAPS in Nepal. Hence, the present research was carried out to assess the extent of IAPS invasion and their impacts in the Panchase area in western Nepal.

\section{Research site and methods}

\section{Study area}

The study was carried out in the Panchase protected forest site high occurrence of the invasive at the junction of Kaski, Parbat and Syangja districts in the Western Development Region of Nepal It lies between latitudes $28^{\circ} 12^{\prime}$ and $28^{\circ} 18^{\prime} \mathrm{N}$, longitudes between $83^{\circ} 45^{\circ}$ and $83^{\circ}$ $57^{\prime} \mathrm{E}$, and altitude ranging from $815 \mathrm{~m}$ to $2,517 \mathrm{~m}$. Considering its high natural resource significance, as well as its potential for eco-tourism, it has been the focus of national, regional and local development strategies and plans (GoN, 2012). The Panchase Protected Forest was gazetted as a 'protected forest' on February 27, 2011, under article 23 of the Forest Act 2002 in recognition of its rich biodiversity, forest resources, as well as its cultural and spiritual values (Suwal et al., 2013). Panchase, which literally means 'five seats' is the meeting place of five hills, and it represents the mid-hills of Nepal. The area received an average annual rainfall of $338 \mathrm{~mm}$ over the period of 25 years from 1985 to 2010 , with the highest rainfall occurring in the monsoon of 1988 with the total rainfall of $4,936.6 \mathrm{~mm}$ (UNDP/MDO, 2006). The area has great biological, cultural and religious diversities as well as natural beauty. The Panchase Lake is considered as a famous site for religious pilgrimage for the people of the area in November (Bhattarai et al., 2014). Although the area has a great diversity of ecosystems and plant species (Aryal and Dhungel, 2009), the likelihood of invasion of different ecosystems is increasing either due to depopulation or erratic rainfall. All the 17 villages of the Panchase area have been invaded by the IAPS such as Ageratina adenophora, Ageratum conyzoides, A. houstonianum, Chromolaena odorata and Eichhornia crassipes (Kunwar and Acharya, 2013).

Bhadaure Tamagi Village Development Committee (VDC) (Fig. 1) of the Panchase Protected forest was selected considering rich biodiversity, altitudinal variation, high outmigration, an expanse of fallow lands, and record of historical invasion. Furthermore, the village has a high occurrence of the invasive alien plant species, with apparent impacts on connected ecosystems (UNDP/MDO, 2006). The VDC covers 2,504.3 ha and has a population of 3,257. The average family size is four, which is less than the national average of 4.88 (GoN, 2012). This is due to the out-migration of more than 50 percent of the local working age population for various purposes. 


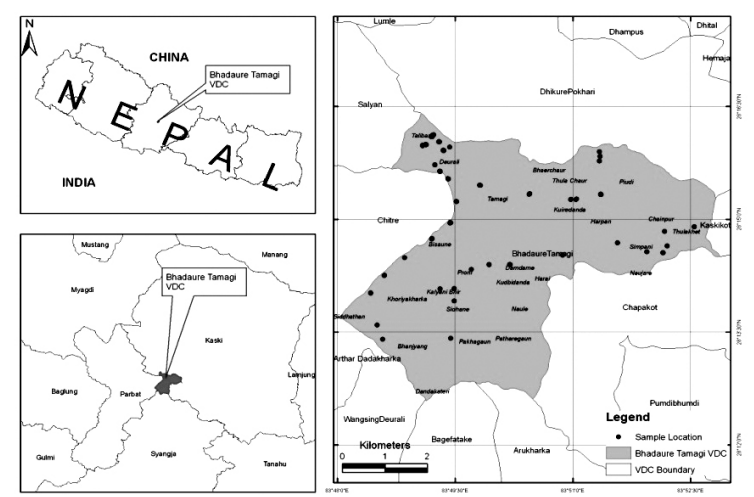

Fig. 1: Location map of the study area

For this study, the VDC was divided into four ecosystem types, namely agriculture, forest, wetlands and grasslands for spatial analysis of the distribution and impacts of invasive plant species (Fig. 2). Forest was found to be the dominant ecosystem, forest, along with grassland covers $76.13 \%$, followed by agro-ecosystem $(22.86 \%)$ and wetland (1.01\%). The Khahare Khola and Harpan Khola are the major river systems that constitute the majority of the wetland ecosystem, followed by the transitional grassland ecosystem (Sharma et al., 2013). The lower belt of the study area, characterized by the dense settlement is used for settlements and farming whereas the upper belt, mostly covered by forest, is traditionally used for herding livestock and pasture.

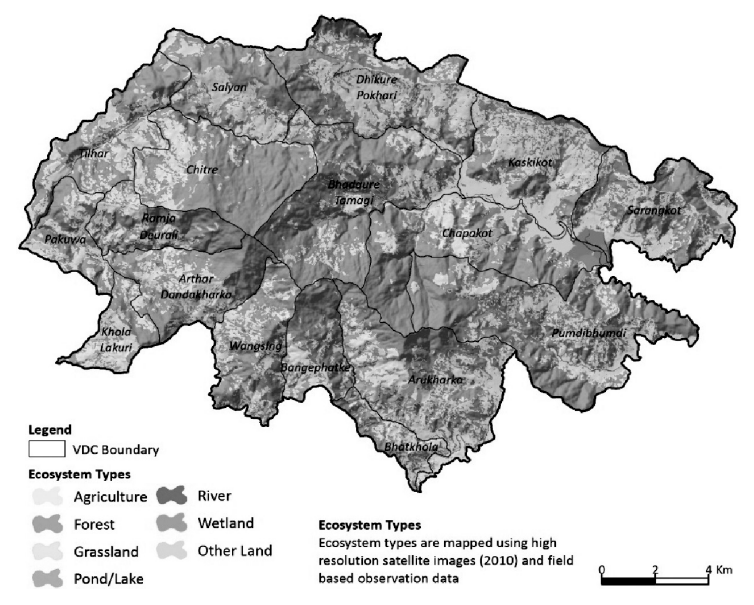

Fig. 2: The study area with different ecosystems

\section{Study methods}

The required information was collected through mainly two approaches; ecological assessment and participatory methods such as community consultation, household questionnaire survey, direct field observation, and group discussion. The spatial analysis was performed using participatory cluster mapping and Geographical Information System (GIS), and the ecological assessment. Furthermore, stakeholder consultations were organized to know the history and intensity of impacts of IAPS; the representatives from the District Forests Office (DFO), Panchase Development Committee as well as the other knowledgeable persons participated in the consultations.

\section{Participatory assessment}

While collecting data, prior informed consent was obtained at different levels. A total of 28 households (nearly $5 \%$ of the total 570 of households) were interviewed using household questionnaires to understand the impact of IAPS on the different ecosystems of the Panchase area and problems of invasion. Six focus group discussions (FGDs) were conducted with farmers CFUGs, club members, NGO representatives, Panchase Protected Forest Council Members and the Mothers' Group Members to gather additional information on the status and effects of IAPS on the different ecosystems. Altogether, 58 respondents participated in the FGDs. Participatory resource mapping was conducted with the locals to identify the most affected areas. In addition, a historical timeline was prepared during the FGDs to document the extent of invasion and its impact of invasion. The study largely relied on the recall method to elucidate the history of introduction, trends and distribution of invasion. Information was validated with the help of the key-informant interviews, especially with the elderly and forest guards. After participatory mapping, an ecological assessment was carried out representing the different ecosystems of the Panchase area.

\section{Ecological assessment}

A rapid ecological assessment was carried out based on the participatory resource mapping representing different ecosystems. The assessment was carried out in December 2012. Depending upon the terrain condition, perpendicular transects within a distance of 50-100 m length were laid on the ground. On either side of the transect, two quadrats, each measuring $10 \mathrm{~m} \times 10 \mathrm{~m}$ were laid (Fig. 3) ensuring the requisite distance and spiral in spinning; thus, one quadrate was feasible in each perpendicular transect and two in each 
parallel transect. Altogether, 108 plots were laid in the field. In each quadrant, two sub-plots measuring $1 \mathrm{~m} \times 1 \mathrm{~m}$ for annual and $2 \mathrm{~m} \times 2 \mathrm{~m}$ for biannual IAPS, respectively were laid. For conducting the ecological study, different sites situated at the different altitudes were sampled (Table 1).

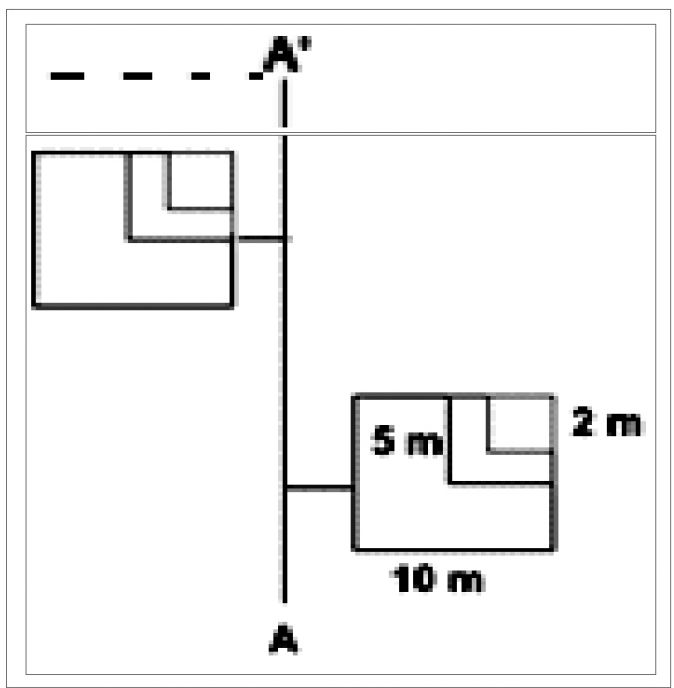

Fig. 3: Lay out of the quadrants and subquadrants in the field

Table 1: Study sites and elevation

\begin{tabular}{llrr}
\hline S.N. & \multicolumn{1}{c}{ Site } & \multicolumn{1}{c}{$\begin{array}{c}\text { Elevation } \\
(\mathbf{m})\end{array}$} & $\begin{array}{c}\text { No. of } \\
\text { quadrats }\end{array}$ \\
\hline 1 & Ghatichina & $821-975$ & 13 \\
2 & Thulakhet & $929-959$ & 19 \\
3 & Chainpur & $1,036-1,136$ & 9 \\
4 & Harpan & $1,214-1,441$ & 12 \\
5 & Damdame & $1,288-1,292$ & 2 \\
6 & Sidhane & $1,326-1,390$ & 6 \\
7 & Kutmidada & $1,337-1,361$ & 12 \\
8 & Deurali & $1,410-1,822$ & 7 \\
9 & Tamagi & $1,440-1,908$ & 6 \\
10 & Bhadaure & $1,502-1,699$ & 8 \\
11 & Ahaldada & $1,860-2,096$ & 2 \\
12 & Bhanjyang & $2,001-2,048$ & 2 \\
13 & Chisapani & $2,058-2,063$ & 10 \\
\hline & Total & & 108 \\
\hline
\end{tabular}

The soil samples were collected to assess the relationship between the soil and the invasive species. The physio-chemical properties (texture, $\mathrm{pH}$ and moisture) of the five soil samples collected were studied to determine whether the IAPS correlated with the soil characteristics. The available climatological records (rainfall and temperature) obtained from the Meteorological Station nearby Lumle, for the period of 19812011, were correlated with the ecological data. The plant species were identified by following Stainton and Polunin (1984), Stainton (1988) and GoN (2001).

\section{Data analysis}

The quantitative data obtained from the household interviews was analyzed using the SPSS 16.0 Software. The climatic characteristics of the study area were assessed in terms of average annual maximum and minimum temperatures and annual precipitation. The suitability analysis was carried out on the basis of the distance and the frequency of the existing species in relation to the landuse, rivers and roads. Similarly, the analysis of the species distribution was conducted by using the Importance Value Index (IVI) as introduced by Cottam and Curtis (1956) for comparison of the species dominance. The IVI provides a quantitative basis for the classification of community, which reflects the overall importance of a species; the IVI for a species is calculated as the sum of its relative frequency, relative density and relative dominance, as follows:

Relative frequency is the frequency of a species in relation to the frequency of all the other species, and is expressed as,

$$
\begin{gathered}
\text { Relative Frequency }(\%)=\frac{\text { Frequency of a Species }}{\text { Total Frequency of all }} \\
\text { the species } \\
\text { (Source: } \text { Raunkiaer, 1934) }
\end{gathered}
$$

Relative density is the density of a species with respect to the total density of all species, and is expressed as,

$$
\text { Relative Density }(\%)=\frac{\text { Density of individual Species }}{\begin{array}{c}
\text { Total density of all the } \\
\text { species }
\end{array}} \times 100
$$

(Source: Zobel et al., 1987)

Finally, the Importance Value Index (IVI) is calculated by using the following formula:

IVI = Relative Frequency (RF) + Relative Density (RD) + Relative Dominance (RDo)

\section{Results and discussion}

\section{Invasive alien plant species and invasion trend}

Invasive species have long been ethno-identified, recognized and locally managed by the local 
communities. Tiwari et al. (2005) have identified, altogether, 166 invasive alien plants species in Nepal. However, we found as many as 194 invasive plant species after updating the record of the Panchase area. Of these, 52 were recorded in the Panchase area alone and 28 were the newly recorded invasive plants.

Altogether, 18 invasive plant species were found to be with higher occurrence in the study area. Of these, 12 (Ageratina adenophora, Ageratum houstonianum, Borreria alata, Chromolaena odorata, Conyza japonica, Eichhornia crassipes, Lantana camara, Parthenium hysterophorus, Phalaris minor, Grevillea robusta, Leucaena leucocephala and Xanthium strumarium) species were of high risk of spreading which has been also reported by Tiwari et al. (2005). The local communities were, however, only aware of the impact of nine species out of which $A$. adenophora and Ageratum conyzoides were more frequent and dense in distribution. They are noted for aggressive and rampant spread.

A. conyzoides and A. adenophora were found to be beyond control, causing detrimental impact upon the local biodiversity by reducing the regeneration of a number of valuable plant species and, thereby, causing negative impact on the livelihood of the local communities. Their ecological importance value index (IVI) showed that $A$. adenophora (135) and A. houstonianum (104) possessed higher values. The higher IVI values indicated that these were the most abundant and notoriously propagated species in the study area; their rampant growth was also observed along the trails. The ecological analysis showed that $A$. adenophora was present throughout the study area. It was, however, more abundant at higher elevations (above 1,500 m). The transition lands between the agricultural land and forest lands, fallow lands and roadsides above $2,000 \mathrm{~m}$ exhibited the greatest degree of invasion; where the preventive and controlling measures were limited in these areas. The low land of the study area was co-dominated by $A$. adenophora and A. houstonianum. A. adenophora was sparsely distributed in all the types of soil and environment throughout the study site; however, the nearby wetlands and grasslands were the most favorable environments for invasion.

In the study site, the impact of IAPS had been apparent over the past three decades; notably,
Conyza japonica became problematic twentyfive years ago (Fig. 4). According to the local communities, C. japonica, Phalaris minor, B. alata, A. adenophora, A. houstonianum and $\mathrm{C}$. odorata were the primary invaders assaulting the native biota of all the subject habitats- agricultural lands, wetlands, forests lands and ruderal lands. The extent of invasion of the species, however, differed by ecosystem. The agricultural lands were notoriously confronted by C. japonica, and further aggravated by the invasion of $P$. minor and $B$. alata. The latter was found to be more common at the banks of the farmlands. The invasion of $A$. adenophora in Panchase was reported fifteen years ago (IUCN, 2013), and its invasion continued to dominate the habitats in the proximity of the wetlands. About $20 \%$ of the forest land, particularly forest fringes were found to be invaded by the IAPS in Panchase.

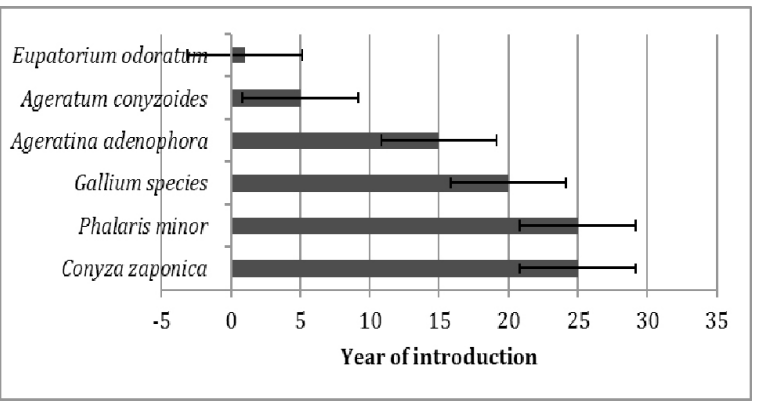

Fig. 4: Graph showing the year of introduction of IAPS in the study area

\section{Driving factors of invasion}

Both anthropogenic and natural factors are responsible for the introduction and spread of IAPS (Rai et al., 2012). During the consultations with the local communities, it came into our notice that the major factors of invasion were the ecology of the invasive plants and their adaptability, outmigration and shift in occupation, agronomic practices followed in the area, topography and soil characteristics, climate change and unplanned road construction. Panchase is facing a high rate of out-migration, causing an acute scarcity of human resources for agriculture (Bhattarai et al., 2014), leaving the entire agricultural lands fallow. As a result, the IAPS got opportunity to grow in open spaces and spread throughout the agricultural ecosystem. More than two-thirds of the respondents claimed that, all of the above causes except climate change and unplanned road construction were responsible for the invasion of $A$. houstonianum while the invasion of $A$. 
adenophora occurred due to all the causes other than the agronomic practices in the study area (Table 2). As the roots of A. houstonianum are densely fibrous and branched, the species tightly anchors the soil, and grows in all ecosystem types including agricultural lands, disturbed sites and degraded areas. It has a high adaptive capability, as it can complete its life-cycle in less than two months, and reproduces mainly from seeds (IUCN, 2013) which are easily dispersed by livestock and wild animals, human clothes, water and agricultural seeds and equipment. The local communities were quite aware about the increasing temperature, and the increase in invasive species was perceived as an aftermath of increasing temperature and rainfall.

The plant invasion was found to be positively but not significantly correlated with the soil $\mathrm{pH}$ $(\mathrm{r}=0.577)$ and soil moisture $(\mathrm{r}=0.738)$, Table 3 ). The soil $\mathrm{pH}$ in the study area was found to have ranged from 4.6 to 6.5 , which is suitable for the growth of IAPS (Borland et al., 2009). The negative correlation value $(\mathrm{r}=-0.84, \mathrm{p}=0.05)$ between the altitude and the IVI revealed that the invasion of the alien plant species (in the study area) decreased with the increase in the altitude.

The temperature varies with the altitudes. The average annual maximum and minimum temperatures in last 30 years (1981-2011) at Lumle, the nearby station, were $20.22^{\circ} \mathrm{C}$ and $11.99^{\circ} \mathrm{C}$, respectively. The field observations showed that the species were mostly abundant at the lower elevations $(1,000-1,500 \mathrm{~m})$ where their growth was also relatively high as a result of comparatively high temperatures. This coincides with the relationship between the altitude and the IAPS as mentioned above.

\section{Impacts of Invasion}

The threat, impact and management problems because of the invasions were severe in the study area. The edges of the forests, agricultural lands and wetlands had severe IAPS intrusion. The grasslands and agricultural lands, as well as the fallow lands and roadsides were found to be highly susceptible to the IAPS (Fig. 5). Although most of the community-managed forests were worth in controlling the spread of IAPS, the ecosystems particularly the forests, wetlands and grazing lands of the VDC were found to be deteriorated most due to the invasion of alien species. The species such as Artemisia indica, Solanum surattense and U. dioica in the fallow lands and Digitaria spp. (Banso), Echinochloa colona (Samo), Eriophorum comosum (Phurke), Ischaemun rugosum (Mallido) and Imperata cylindrica (Siru) in the agricultural lands were threatened by the IAPS within the study site. All the ecosystems were found to be susceptible to invasion, the ecosystems intertwined with higher level of human interventions. Grazing,

Table 2: Causes for the spread of IAPS in the study area

\begin{tabular}{llcc}
\hline \multirow{2}{*}{ S. N. } & \multirow{2}{*}{ Causes } & \multicolumn{2}{c}{ Respondent \% (n= 28) } \\
\cline { 3 - 4 } & & A. houstanianum & A. adenophora \\
\hline 1. & Biology of IAPS and their adaptability & 78.6 & 85.7 \\
2. & Out-migration and shift in occupations & 92.9 & 89.3 \\
3. & Agronomic practices & 78.6 & 53.6 \\
4. & Topography and soil characteristics & 78.6 & 82.1 \\
5. & Climate change & 64.3 & 78.6 \\
6. & Unplanned road construction & 53.6 & 85.7 \\
\hline & & Source: Field Survey, December 2012
\end{tabular}

Table 3: Indicators for the spread of IAPS in the study area

\begin{tabular}{lccc}
\hline Indicators & Average & Range & Correlation coefficient \\
\hline Altitude $(\mathrm{m})$ & 1,307 & $1,000-1,500$ & $-0.84 *$ \\
Soil $\mathrm{pH}$ & 5.2 & $4.6-6.5$ & 0.577 \\
Soil moisture & $42 \%$ & $34-45 \%$ & 0.738 \\
\hline
\end{tabular}

Note: $*$ significant at $95 \%$ confidence level 
agriculture and fallow lands and roadsides were highly susceptible to invasion.

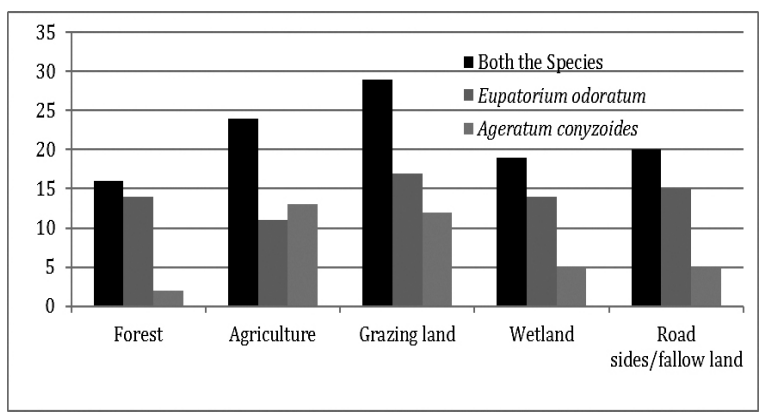

Fig. 5: Different ecosystems susceptible to IAPS in the study area

In the agricultural fields, IAPS, namely $A$. houstonianum, B. alata, and P. minor were known to replace the native species, as well as preventing their natural regeneration. Many forb species, such as A. indica, S. surattense and U. dioica in the fallow lands and Hypoxis aurea and Scrophularia species on the agricultural lands were imperilled by the invasion of $A$. houstonianum, $B$. alata, and P. minor. A. houstonianum has adverse impacts on most of the agricultural crops, as it exploits the nutrients and fertilisers supplied to the main crops. Agricultural crops, particularly ginger, millet, rice and grasses, were outcompeted by Ageratum. The invasion of A. conyzoides, A. adenophora, and $C$. odorata has reduced the production of cereal crops and grasses in the Panchase area, causing economic losses from agriculture business. The local communities reported that usually, about $273 \mathrm{~kg}$ of rice was produced in a ropani $(500$ $\mathrm{m}^{2}$ ) of agricultural land in Chainpur, but after the invasion of $A$. houstonianum, rice production reduced to about $182 \mathrm{~kg}$.

Forest fringes, roadsides and fallow lands were previously dominated by $A$. indica, S. surattense, and $U$. dioica. These species failed to maintain their biomass in the changing climatic and land use conditions, and their dominance was overtaken by opportunistic and invading alien plant species. Besides their ecological traits, their chemical traits also made them fetid and unpalatable, supporting notorious growth. Ageratina contains cadinene sesquiterpenes which is allelopathic, and controls associated vegetation (Kundu et al., 2013). It is also poisonous to horses (Bohlmann and Gupta, 1981; Baruah et al., 1994). Similarly, in agricultural fields, grasses such as Banso, Samo, Phurke, Mallido and Siru have been threatened because of invasion of $A$. conyzoides, B. alata, and P. minor in the agriculture fields. The lower area of the Bhadaure Tamagi VDC was densely populated by subsistence farmers, and livestock rearing was an integral part of their livelihood (Bhattarai et al., 2012).

According to the local communities, the impact of A. houstonianum on livestock was more severe; in the last five years, there were five cases of livestock mortality, particularly of buffalo. In general, buffalo and other livestock, except goat, do not forage on A. houstonianum, but sometimes they inadvertently feed on the IAPS while feeding on other grasses and forbs. The cases generally occur in the spring, when the plant's flowers are in full bloom. According to their version, the animal's abdomen enlarges after feeding on A. houstonianum compelling it to defecate, but the animal sometimes looses its life too. The local communities reported that along with the adverse impacts, IAPS had some positive impacts too. A. adenophora had been used as a green energy resource for composting and soil fertility enhancement in the locality. The practice of using $A$. adenophora as green manure had been increasing at the study site.

\section{Invasion}

Out of the 100 invasive alien worst weed species found in the world (Lowe et al., 2000), eleven are found in Nepal (Sankaran et al., 2005). The seven important alien invasive species (Arundodonax, Chromolaena odorata, Eichhornia crissepes, Hedychium gardnerianum, Hiptage benghalensis, Imperata cylindrica, Lantana camara, Leucaena leucocephala, Mikania micrantha, Opuntia stricta and Rubus ellipticus) found in the Asia Pacific region are also found in Nepal, and all the species except $M$. micrantha are found in the Panchase area. Among the 14 worst species, nine species were prevalent in the Bhadaure Tamagi VDC, of which $A$. conyzoides and $A$. adenophora were found to be the most problematic species. The determinants of plant invasiveness per se are extremely complex (Rejmanek, 2005). Although the IAPS are found in all the ecosystem types, the results showed that $A$. adenophora was dominant in all the ecosystems except the agricultural land. It is found that open areas were found to be conducive for the establishment of $A$. adenophora. This is because most of the IAPS are light demander and cannot be found inside dense forests. Therefore, 
their diversity and distribution were found to be homogenous throughout the study site. $A$. adenophora was also the first species to colonize the degraded areas and prevent other plants from establishing themselves. In the study area, the open grazing system had been practiced since a long time ago. In this system, generally the cattle are left free in the area for grazing without human-care mainly during summer (3-4 months), the land is frequently browsed by these cattle, as well as other wild animals. Therefore, the area had become more prone to biological invasion, and the trampling by the domestic and wild animals had accelerated high invasion proliferation in the grasslands. According to the local farmers, Hypoxis aurea began to spread aggressively in the agricultural fields of the area seven years ago due to excessive use of nitrogen chemical fertilizer.

Biologists, ecologists and conservationists have failed to manage the invasive species for a long time (Bhagwat et al., 2012). In the study area, the plant invasion was found to be fueled by anthropogenic interferences such as habitat degradation, and abandoned of the agricultural lands, as a result of youth outmigration, had provided adequate space for the invasion of IAPS. This had created space for the proliferation of several invasive species in the area, which is consistent with the findings of Maren et al., 2013. Furthermore, the agronomic practices in the study area was found to be changing, for instance, the use of organic compost manure in agricultural farming was found to be decreasing while the use of chemical fertilizer increasing. Similar observation was also reported by Timsina et al., (2011) in their studies in Majhuwa Deurali of the Gorkha district, Majhitar of the Nuwakot district and Kirtipur of the Kathmandu district in the central part of Nepal. As reported by Dukes and Mooney (1999), the findings of this study shows that several IAPS had quickly established in a new soil, and thus had covered almost all the open areas and newly constructed roadsides (Yasuyuki et al. 2010).

\section{Impact}

Although all the ecosystems in the study area were found to be susceptible to invasion, the ecosystems exposed to a higher level of human interventions such as agricultural lands and grasslands were more susceptible to invasion of IAPS, which is consistent with the findings of Yelenik et al., (2007). Forest lands were found to be the least affected in the study site as they were more diverse, (Bhattarai et al., 2012), closecanopied and distantly located. The invasive plant species are often shaded by trees and lianas in forests (Rouw, 1996), and their invasion is slowed (Tjitrosemito, 1996). As a result, dense and diverse forests are more resistant to ecological invasion (Pimm, 1984). However, only about 20 percent of the forests, particularly at their edges in the study area were found to be invaded by the invasive plant species as being light demander species.

The invasive plants were found to be growing in a wide range of soils in the open areas. The soil texture in the agricultural lands in the study area was found to be silt-clay. The highest population of A. houstonianum in the agricultural land showed that they preferred silt- clay whereas the abundance of $A$. adenophora in the roadside and rangeland shows that the species preferred coarse soil. A. houstonianum has adverse impacts on most of the agricultural crops, as it exploits nutrients and fertilizers supplied to the main crops. IAPS affect the dynamics and composition of soil and affect the ecosystem functions, such as soil nutrient cycling (Yelenik et al., 2007) and soil chemistry (Randall and Marinelli, 1996).

The local communities were living in the lower area of the study site where livestock rearing was an integral part of their livelihoods (Bhattarai et al., 2012; Rai and Scarborough, 2015). For this reason, fodder collection was the second most important biomass out-take, especially in dry and lean periods when on-farm fodder particularly sparse. The species preferred by the local people for lopping fodder were Brassaiopsis hainla, Ficus lacor, F. glaberrima, F. hispida, Streblus asper, Eurya accuminata, Prunus species, Quercus lamellosa and Q. semecarpifolia (Bhattarai et al., 2012). Their productivity was, however, constrained by $A$. houstonianum, because both use the resources base of hedgerows and embankments of farms. The inadequate labour in the study site had also led the agriculture lands and grasslands to be less unattended, resulting into rampant spread of invasive plant species. According to the local inhabitants, the indigenous agricultural crops such as ginger, millet, rice and grasses were outcompeted by Ageratum whereas the forestry species were outpaced by Ageratina. The invasion of $A$. conyzoides, A. adenophora, and $C$. odorata had reduced the production of 
cereal crops and grasses in Kaski district (Bhusal, 2009). According to Oerke et al., (1995), there was a loss of $13 \%$ of the agricultural output due to weeds.

\section{Usefulness of alien invasive plants}

Most of the alien invasive plants have adverse effects both on forests and agriculture lands. Nevertheless, they also have some use values, such as medicinal, edible as a vegetable, fodder for cattle, preparing manure, hedge fencing and erosion control. The practice of using $A$. adenophora as a green manure is increasing the study site. Green manure of $A$. adenophorahas contributed to increasing nutrient supply to the agricultural land thereby increasing yields of rice (Bhattarai et al., 2006). Sun et al.,(2004) has found that the manure contains $0.372 \%$ of total nitrogen, $0.062 \%$ of total phosphorus and $0.580 \%$ of total potassium, as well as calcium, magnesium, iron, sulphur, silicon, zinc, boron (Sun et al., 2004). Therefore, promotion of the use of $A$. adenophora as a green manure is important.

Traditionally, A. adenophora has long been used as a cattle-bedding material, in several parts of the country (Shrestha, 1989). The leaves of $A$. adenophoraare used for controlling bleeding from cuts. Its medicinal properties have already been documented (Oladejo et al., 2003). In addition, $A$. adenophora is being used in the study site to produce bio-briquettes. The richness and distribution of invasive plants in the study area can be a good resource for an invasive-plantbased entrepreneurship. However, Bhagwat et al., (2012) recommend cautious use of invasive species through adaptive management approach, which provides a favorable environment for non-timber forest species from which the local communities can benefit.

\section{Conclusion}

As seen elsewhere, biological invasion of IAPS causes destruction and out-competition with indigenous species. The replacement of native species by IAPS is a gradual process, so it is difficult to show the evidence of direct replacement, but we succeeded in tracing the history of increasing the spread of invasive species in the Panchase area. Artemisia indica, Solanum surrattense and Urtica dioica were threatened by the invasion of $A$. houstonianum,
Borreria alata, and Phalaris minor showing the complexities of the local ecology and socioeconomy. The invasion was more severe at the edges of the forest and agricultural lands and also the wetlands where the onslaughts of $A$. adenophora were persistent. The invasion was less in dense forests, implying that close canopy forests are less sensitive to invasive species, and routine management can check the threats of invasive species. Nevertheless, IAPS can also be managed tactfully by using the resources wisely instead of destroying them haphazardly. In addition, the bare ground should be minimized to control further spread of IAPS (Feng et al., 2002) as far as possible. In the context of climate change, social transformation, and cultural evolution, cautious use of non-indigenous resources is often touted, and controlled use of invasive species can be a positive asset for the management of the site. However, to put it in practice, the local communities along with the forest officials should be taught to include IAPSs management activities in their management plans.

\section{References}

Aryal, A. and Dhungel, S. K., 2009. Species diversity and distribution of bats in Panchase, a region of Nepal. Tiger Paper 36 (2): 14-18.

Banerji, N. L. 1958. Invasion of Eupatorium glandulosum ( $E$. adenophorum) in east Nepal. Bulletin of Botanical society $10(\mathbf{1 , 2})$ : 14-18.

Baruah, N. C., Sharma, J. C., Sharma, S. and Sharma, R. 1994. Seed germination and growth inhibitory cadinene from Eupatorium adenophorum. Journal of Chemical Ecology 20: $1885-1895$.

Bhagwat, S. A., Breman, E., Thekaekara, T., Thornton, T. F. and Willis, K. J. 2012. A battle lost? Report on two centuries of invasion and management of Lantana camara L. in Australia, India and South Africa. PLoS ONE 7(3): e32407. doi:10.1371/journal. pone.0032407, 17 May, 2014.

Bhattarai, K. R., Måen, I. E. and Subedi, S. C. 2014. Biodiversity and invasibility: distribution patterns of invasive plant species in the Himalayas, Nepal. Journal of Mountain Science 11 (3): 688-696. 
Bhattarai, K. R., Maren, I. E. and Chaudhary, R. P. 2012. Medicinal plant knowledge of the Panchase region in the middle hills of the Nepalese Himalaya. Banko Janakari 21 (2): 31-39.

Bhattarai, S., Bhudathoki, K. and Serchan, D. 2006. Organic farming: its role in soil fertility, effect on crop production, constraints and future strategy. Proceeding of National workshop on organic farming. District Agriculture Development Office, Department of Agriculture, Kathmandu, Nepal, 131-137.

Bhusal, Y. R. 2009. Local Peoples' Perceptions on Climate Change, Its Impacts and Adaptation Measures in Mid-Mountain Region of Nepal: A case Study from Kaski District (Thesis). Institute of Forestry, Pokhara, Nepal, 1-19.

Bohlmann, F. and Gupta, R. K. 1981. Six cadinene derivatives from Ageratina adenophora. Phytochemistry 20: 1432-1433.

Borland, K., Campbell, S., Schillo, R., and Higman, P. 2009. A Field Identification Guide to Invasive Plants in Michigan's Natural Communities. Michigan State University Extension, USA.

Burgiel, S. W. and Muir, A. 2010. Invasive Species, Climate Change and Ecosystembased Adaptation: Addressing Multiple Drivers of Global Change. Global Invasive Species Programme, Washington DC, USA, 30.

CBD. 1992. United Nations Environment Programme. Convention on Biological Diversity (CBD). www.biodiv.org. 17 May, 2014.

CBD. 2002. Alien species that threaten ecosystems, habitats or species (Endnote I). Secretariat of the Convention on Biological Diversity (CBD). Decision VI/23, Montreal, Canada.

CBD. 2008. Alien species that threaten ecosystems, habits or species. Convention on Biological Diversity. Article $8(\mathrm{H})$ ): Report on Consultations regarding international standards. FAO, Rome 18-22 February 2008.

Dukes, J. H. and Mooney, H. A. 1999. Does global change increase the success of biological invaders? Trends in Ecology and Evolution 14: 135-139.

Feng, H. L., Cao, H. L., Liang, X. D., Zhou, X. and Ye, W. H. 2002. The distribution and harmful effect on Mikania micrantha in Guangdong. Journal of Tropical and Subtropical Botany 10: 263-270 (in Chinese).

GoN. 2001. Flowering Plants of Nepal (Phanerogams). Department of Plant Resources, Ministry of Forests and Soil Conservation, Government of Nepal (GoN), Kathmandu, Nepal, 399.

GoN. 2012. Protected Forest of Nepal. Department of Forest, Ministry of Forests and Soil Conservation, Government of Nepal (GoN), Kathmandu, Nepal, www.dof.gov.np 17 June 2014.

IPCC. 2007. Impacts, Adaptation and Vulnerability. Working Group II Contribution to the Intergovernmental Panel on Climate Change Fourth Assessment Report. Summary for Policy Makers. Intergovernmental Panel on Climate Change (IPCC), Geneva, Switzerland.

IUCN. 2000. Guidelines for the Prevention of Biodiversity Loss due to Biological Invasion. International Union for Conservation of Nature (IUCN), Gland, Switzerland, 1-24.

IUCN. 2005. Benefit Beyond Boundaries. Proceedings of the 5th IUCN World Parks Congress. International Union for Conservation of Nature (IUCN), Gland, Switzerland and Cambridge, UK, ix +306 .

Kundu, A., Saha, S., Walia, S. and Annapurna, K. 2013. Cadineneses quiterpenes from Eupatorium adenophorum and their antifungal activity. Journal of Environmental Science and Health, Part B: Pesticides Food Contaminants and Agricultural Wastes 48 (6): 516-522.

Kunwar, R. M. and Acharya, R. P. 2013. Impact Assessment of Invasive Plant Species in Selected Ecosystems of Bhadaure Tamagi VDC, Kaski, Nepal. IUCN Nepal, Kathmandu, 1-84.

Kunwar, R. M., Baral, K., Paudel, P., Acharya, R. P., Thapa-Magar, K. B. and Cameron, M. 
2016. Land-use and socioeconomic change, medicinal plant selection and biodiversity resilience in far western Nepal. PLoS ONE 11 (12): e0167812. doi:10.1371/journal. pone. 0167812

Lodge, D. M., Williams, S., Macisaac, H., Hayes, K., Leung, B., Loope, L., Reichard, S., Mack, R. N., Moyle, P. B., Smith, M., Andow, D. A., Cartlon, J. T. and Mchichael, A. 2006. Biological invasions: recommendations for policy and management. Position Paper for the Ecological Society of America. Ecological Applications 16: 2034-2054.

Lowe, S., Browne, M., Boudjelas, M. and Poorter, M. 2000. 100 of the World's Worst Invasive Alien Species. Invasive Species Specialist Group (The International Union for the Conservation of Nature), Auckland. www. issg.org/booklet.pdf accessed on 17 May, 2016

Maren, I., Bhattarai, K. R., and Chaudhary, R. P. 2013. Forest Ecosystem Services and Biodiversity: The Resource Flux from Forests to Farms in the Himalayas. Draft report. Environmental Conservation, Kathmandu, Nepal.

Matthews, S. and Brand, K. 2004. Africa Invaded: The Growing Danger of Invasive Alien Species. Global invasive species programme, Cape Town, South Africa.

Mooney. H. A, Mack, R. N, McNeely, J. A, Neville, L. E, Schei, P. J. and Waage, J. K. (eds) 2005. Invasive Alien Species: a new synthesis (Scope Series 63). Island Press, Washington DC, USA.

Mooney, H. A. and Hobbs, R. J. 2000. Invasive Species in a Changing World. Island Press, Washington DC, USA, 384.

Oerke, E. C., Dehne, H. W., Schohnbek, F. and Weber, A. 1995. Crop Production and Crop Protection: Estimated Losses in Major Food and Cash Crops. Elsevier, Amsterdam and New York, USA 808.

Oladejo, O. W., Imosemi, I. O., Osuagwu, F. C., Oyedele, O. O., Oluwadara, O. O., Ekpo, O. E., Aiku, A., Adewoyin, O. and Akang, E. E. U. 2003. A comparative study of the wound healing properties of honey and Ageratum conyzoides. African Journal of Medical Sciences 32: 193-196.

Pimm, S. L. 1984. The complexity and stability of ecosystems. Nature 307: 321-6.

Poudel, B. S. and Thapa, H. B. 2012. An assessment of existing studies on invasive alien plant species of Nepal. Banko Janakari 22 (1): 28-36.

Rai, R. K., Scarborough, H., Subedi, N. and Lamichhane, B. 2012. Invasive plants - Do they devastate or diversify rural livelihoods? Rural farmers' perception of three invasive plants in Nepal. Journal of Nature Conservation 20: 170-176. doi:10.1016/j. jnc.2012.01.003 accessed on 12 May, 2015.

Rai, R. K. and Scarborough, H. 2015. Understanding the Effects of the Invasive Plants on Rural Forest-dependent Communities. Small-scale Forestry $\mathbf{1 4 . 1}$ (2015): 59-72.

Randall, J. and Marinelli, J. 1996. Invasive Plants: Weeds of the Global Garden. Brooklyn Botanic Garden Club, Inc. Handbook No. 149: 111.

Raunkiaer, C. 1934. Botanical Studies in the Mediterranean Region. Ch. 17 in the Life Forms of Plants and Statistical Plant Geography, 547-620.

Rejmanek, M. 2005. Invasive plants: Approaches and predictions. Austral Ecology 25: 497506.

Richardson, D. M. and Higgins, S. I. 1998. Pines as invasion in the Southern hemisphere. In Ecology and biogeography of Pinus (ed) Richardson, D. M. Cambridge University Press, UK 450-473.

Rouw, A. D. 1996. Chromolaena odorata in the farming systems of South-West Côte d'Ivoire. Proceeding of distribution, ecology and management of Chromolaena odorata. ORSTOM, ICRAF and University of Guam, Mangilao, GUAM, USA, 76-87.

Sankaran, K. V., Murphy, S. T. and Sreenivasan, S. A. 2005. When good trees turn bad: the unintended spread of introduced plantation tree species in India, 39-107. 
Sharma, B. K., Timilsina, K., Rai, R. and Joshi, A. 2013. Biodiversity Resource Inventory: Ecosystem Assessment of Bhadaure Tamagi VDC, Panchase, Nepal. IUCN Nepal, Kathmandu, Nepal.

Shrestha, T. B. 1989. Development of the Arun River Basin. Nepal: Country report on Biological Diversity. Kathmandu, Nepal, 133.

Stainton, A. 1988. Flowers of the Himalaya: A Supplement. Oxford University Press, New Delhi, India, 86.

Stainton, A. and Polunin, O. 1984. Flowers of the Himalaya. Oxford University Press, New Delhi, India, 580.

Sun, X. Y., Lu, Z. H. and Sang, W. G. 2004. Review on studies of Eupatorium adenophorum-an important invasive species in China. Journal of Forestry Research 15 (4): 319-322.

Timsina, B., Shrestha, B. B., Rokaya M. B. and Münzbergová, Z. 2011. Impact of Parthenium hysterophorus L. invasion on plant species composition and soil properties of grassland communities in Nepal. Flora-Morphology, Distribution. Functional Ecology of Plants 206 (3): 233-240.

Tiwari, S., Siwakoti, M., Adhikari, B. and Subedi, K. 2005. An Inventory and Assessment of Invasive Alien Plant Species of Nepal. IUCN - The World Conservation Union, Nepal, viii+114.
Tjitrosemito, S. 1996. The management of Chromolaena odorata. In Proceedings of the Third International Chromolaena Workshop on distribution, ecology and management of Chromolaena odorata (ed) Robinson, $\mathrm{H}$. ORSTOM, ICRAF and University of Guam, Mangilao, GUAM, USA, 135-142.

UNDP/MDO. 2006. Panchase Biodiversity Management Project Report. United Nations Development Programme/ Machhapuchhre Development Organization (UNDP/MDO), UNDP/GEF/SGP, Kaski Nepal.

Yasuyuki, K., Bhaskar, S., Tasong, M., Hui, T., Tomo, R. and Kazuo, A. 2010. Roadside Distribution Patterns of Invasive Alien Plants along an Altitudinal Gradient in Arunachal Himalaya, India. Mountain Research and Development 30 (3): 252-258.

Yelenik, S. G., Stock, W. D. and Richardson, D. M. 2007. Functional group identity does not predict invader impacts: Differential effects of nitrogen-fixing exotic plants on ecosystem function. Biological Invasions 9: 117-125.

Zobel, D. B., Yadav, U. K., Jha, P. K. and Behan, M. J. 1987. A Practical Manual for Wcology. Rani Printing Press, Kathmandu, Nepal. 